\title{
Development of a Fast Thermal Model for Calculating the Temperature of the Interior PMSM
}

\author{
Qixu Chen, Dechen Wu, Guoli Li *, Wenping Cao, Zhe Qian (D) and Qunjing Wang
}

National Engineering Laboratory of Energy-Saving Motor \& Control Technology, Ministry of Education Engineering Research Center of Power Quality, Anhui Collaborative Innovation Center of Industrial Energy-Saving and Power Quality Control, Anhui University, Hefei 230601, China; qixuchen2020@ahu.edu.cn (Q.C.); Z20301159@stu.ahu.edu.cn (D.W.); 19122@ahu.edu.cn (W.C.); zheqian2@ahu.edu.cn (Z.Q.); wangqunjing@ahu.edu.cn (Q.W.)

* Correspondence: liguoli@ahu.edu.cn

check for updates

Citation: Chen, Q.; Wu, D.; Li, G.;

Cao, W.; Qian, Z.; Wang, Q

Development of a Fast Thermal Model for Calculating the Temperature of the Interior PMSM. Energies 2021, 14, 7455 https://doi.org/10.3390/en14227455

Academic Editor: Pedro

Roncero-Sanchez

Received: 8 October 2021

Accepted: 2 November 2021

Published: 9 November 2021

Publisher's Note: MDPI stays neutral with regard to jurisdictional claims in published maps and institutional affiliations.

Copyright: (C) 2021 by the authors Licensee MDPI, Basel, Switzerland. This article is an open access article distributed under the terms and conditions of the Creative Commons Attribution (CC BY) license (https:/ / creativecommons.org/licenses/by/ $4.0 /)$.

\begin{abstract}
A $40 \mathrm{~kW}-4000$ rpm interior permanent magnet synchronous machine (IPMSM) applied to an electric vehicle (EV) is introduced as the study object in this paper. The main work of this paper is theoretical derivation and validation of the first-order and multi-order transient lumped-parameter thermal network (LPTN) for the development of a fast thermal model. Based on the first-order LPTN built, the study finds that the heat transfer coefficient of fluid and thickness of the air gap layer are the main influencing factors for the final temperature and time of reaching the steady state. The larger the heat transfer coefficient of fluid is, the lower the steady node temperature is. The smaller the air layer thickness is, the lower the steady node temperature is. The multi-order LPTN theory is further deduced based on the extension of the first-order LPTN. For the constant load and rectangular periodic load, transient node temperatures of the IPMSM are obtained by modeling and solving the first order inhomogeneous differential equations. Temperature rise curves and efficiency maps of the IPMSM under load conditions are realized on a dynamometer platform. The FLUKE infrared-thermal imager and the thermocouple PTC100 are used to validate the mentioned method. The experiment shows that the LPTN of the IPMSM can accurately predict the node temperature.
\end{abstract}

Keywords: interior permanent magnet synchronous machine (IPMSM); lumped-parameter thermal network (LPTN); conduction and convection

\section{Introduction}

The IPMSM has high power density and torque density, which is widely used as an EV powertrain. The large amount of heat as a byproduct causes a significant temperature rise in the motor. Therefore, it is necessary to accurately predict the motor temperature distribution in advance.

A lumped-parameter thermal network (LPTN) model is always used to predict the node temperature of various electric machines. Transient temperature rises of part nodes are calculated by solving differential equations [1-10].

A full-order LPTN model was built in $[1,2]$. The LPTN model, combining electromagnetic finite-element analysis (FEA) with a thermal resistance network, is built based on the law of heat flux balance in two continuous iterative calculations [1]. The steady-state and transient-state solution of the LPTN model are solved numerically with the fourth-order Runge-Kutta method and the Gauss-Seidel method to predict the temperatures of a $7.5 \mathrm{~kW}$ induction machine [2].

A low computational cost thermal model with order reduction is built for the online prediction of the winding temperature of PMSMs. A set of experimental measure temperatures from direct current (DC) tests is used for calibrating the generic thermal model of induction machines. At the same time, several duty cycles are considered in [3-7]. 
An infrared thermal imager was adopted to validate surface temperature distribution $[8,9]$. A convective heat transfer coefficient has a big impact on the temperature rise of the machine [10-12]. The heat transfer coefficient is deduced theoretically in [8], analyzed by a coupled electromagnetic and thermal model in [9] or evaluated by the average Nusselt number in the stator channels between adjacent teeth [10]. The steady-state thermal network analysis and experiment of a $25 \mathrm{~kW}$ IPMSM with "- " type PM per pole was finished in [13].

Although the above studies have carried out a lot of valuable work in predicting the temperature rise of nodes, some aspects still need improvement as follows.

A complex steady or transient LPTN needs to calculate many geometric and thermal parameters, such as heat capacity, thermal resistance and power loss. In order to reduce the computation burden, it is necessary to analyze a reduced-order model. A full LPTN model usually consists of basic first-order transient thermal network elements. Differences in the type of thermal network unit and factors influencing its temperature rise are not analyzed. In addition, the change in node temperature rise under complicated conditions is seldom discussed in the above studies.

In this paper, thermal resistance value is comparatively calculated for the " $\mathrm{H}$ ", " + " and "I" types of LPTN units. The first-order LPTN is studied using the exponential decay function and the exponential iteration method. A multi-order transient LPTN method of the IPMSM is derived, which takes constant load and rectangular periodic load into account. The exponential decay fit function from the first order to the third order is used to match the measured temperature curve of stator winding. Finally, an IPMSM prototype with a 48-slot/8-pole combination is manufactured and tested. A load experiment is set up under the condition of multiple load cases. Winding temperature, phase current waves, efficiency map and infrared thermal image are measured using the dynamometer platform.

\section{Thermal Resistance Calculation of Thermal Network Unit}

Based on three types of thermal network unit, namely " $\mathrm{H}^{\prime \prime}$, "+" and " $\mathrm{I}$ " type, the exponential decay function method and the exponential decay iteration method are deduced. The two methods are used to calculate the first-order LPTN. For a given constant power loss and total heat flux, the bigger the convection heat transfer coefficient value, the lower the steady-state temperature of the yoke iron core. The geometry parameters of a general hollow cylinder and its unfolded brick are given in Figure 1. It also considers different heat source locations relative to the center of mass [14]. The definitions of the parameters are given in Figure 1.

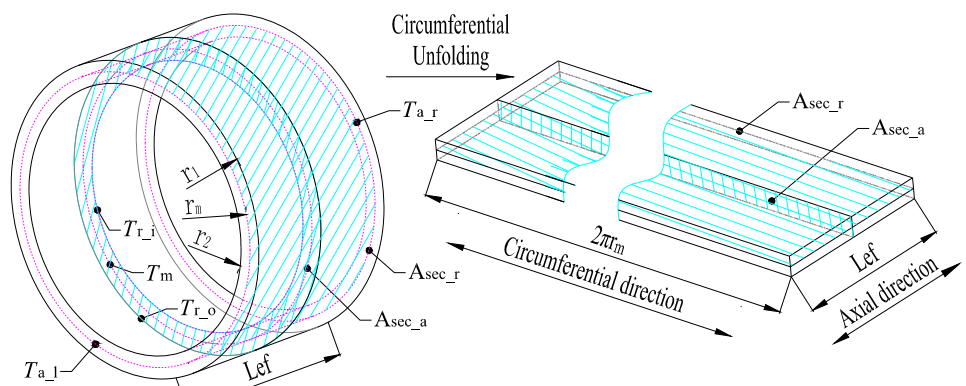

(a)

(b)

Figure 1. Component definition (a) hollow cylinder, (b) unfolded brick.

Thermal network units of " $\mathrm{H}$ " type, "+" type and " $\mathrm{I}$ " type are adapted to the geometric shape of torus and brick. Thermal network units of " $\mathrm{H}$ " type, "+" type and " $\mathrm{I}$ " type define thermal resistance, thermal capacitance, and power loss, which are shown in Figure $2 \mathrm{a}-\mathrm{c}$, respectively. 


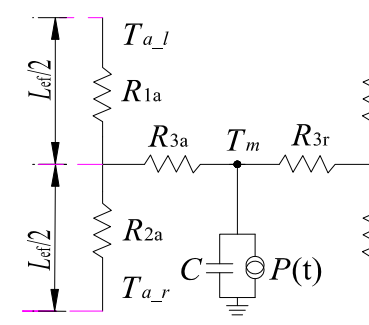

(a)
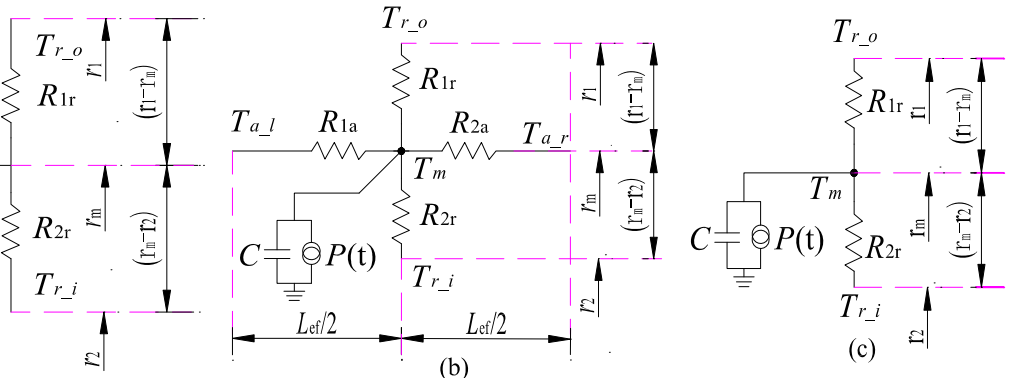

(c)

Figure 2. Definition of thermal network unit. (a) "H" type, (b) "+" type, (c) "I" type.

Heat resistance $R_{\text {cond }}$ is the inverse of heat conductance $G_{c o n d}$, which is given by [14]

$$
R_{\text {cond }}=\frac{l}{\lambda A_{\text {sec }}}, G_{\text {cond }}=\frac{1}{R_{\text {cond }}}
$$

where $l$ is the length in the direction of thermal conductivity $(\mathrm{m}), \lambda$ is the coefficient of thermal conduction $(\mathrm{W} / \mathrm{m} \cdot \mathrm{K})$ and $A_{s e c}$ is the cross-section perpendicular to the direction of thermal conduction $\left(\mathrm{m}^{2}\right)$.

The equivalent thermal conductance $G_{m a t 1,2}$ of two kinds of materials with or without assembly clearance is considered as follows [14].

$$
\left\{\begin{aligned}
G_{m a t 1,2} & =\frac{1}{1 / G_{m a t 1}+1 / G_{a i r}+1 / G_{m a t 2}} \\
G_{m a t 1,2} & =\frac{1}{1 / G_{m a t 1}+1 / G_{m a t 2}}
\end{aligned}\right.
$$

where $G_{a i r}$ is the thermal conductance of air.

\subsection{Thermal Network Unit of " $H$ " Type}

The thermal network unit of " $\mathrm{H}$ " type includes radial and axial thermal resistance $\left(R_{1 \mathrm{r}}, R_{2 \mathrm{r}}, R_{1 \mathrm{a}}, R_{2 \mathrm{a}}\right)$, which are given in Figure $2 \mathrm{a}$ and Table 1.

Table 1. Thermal resistance definition of " $\mathrm{H}^{\prime}$ type [15-19].

\begin{tabular}{lc}
\hline Radial $\boldsymbol{R}_{\mathbf{1} \mathbf{r}}, \boldsymbol{R}_{\mathbf{2} \mathbf{r}}, \boldsymbol{R}_{\mathbf{3} \mathbf{r}}$ & Axial $\boldsymbol{R}_{\mathbf{1 a}}, \boldsymbol{R}_{\mathbf{2 a}}, \boldsymbol{R}_{\mathbf{3 a}}$ \\
\hline$R_{1 r}=\frac{1}{4 \pi \lambda_{r} l}\left(1-\frac{2 r_{2}^{2} \ln \left(r_{1} / r_{2}\right)}{r_{1}^{2}-r_{2}^{2}}\right)$ & $R_{1 a}=\frac{l}{2 \pi \lambda_{a}\left(r_{1}^{2}-r_{2}^{2}\right)}$ \\
$R_{2 r}=\frac{1}{4 \pi \lambda_{r} l}\left(\frac{2 r_{1}^{2} \ln \left(r_{1} / r_{2}\right)}{r_{1}^{2}-r_{2}^{2}}-1\right)$ & $R_{2 a}=\frac{l}{2 \pi \lambda_{a}\left(r_{1}^{2}-r_{2}^{2}\right)}$ \\
$R_{3 r}=-\frac{\left(r_{1}^{2}+r_{2}^{2}\right)}{8 \pi \lambda_{r} l\left(r_{1}^{2}-r_{2}^{2}\right)}+\frac{r_{1}^{2} r_{2}^{2} \ln \left(r_{1} / r_{2}\right)}{2 \pi \lambda_{r} l\left(r_{1}^{2}-r_{2}^{2}\right)^{2}}$ & $R_{3 a}=\frac{-l}{6 \pi \lambda_{a}\left(r_{1}^{2}-r_{2}^{2}\right)}$ \\
\hline
\end{tabular}

\subsection{Thermal Network Unit of "+" Type}

The thermal network unit definition of "+" type includes radial and axial thermal resistance $\left(R_{1 \mathrm{r}}, R_{2 \mathrm{r}}, R_{1 \mathrm{a}}, R_{2 \mathrm{a}}\right)$, as shown in Figure $2 \mathrm{~b}$. We assume here that heat source location coincides with a center of mass. Here, middle radius is given as $r_{\mathrm{m}}=\left(r_{1}+r_{2}\right) / 2$. Its thermal resistance is calculated in Table 2.

Table 2. Thermal resistance definition of "+" type.

\begin{tabular}{cc}
\hline Radial $\boldsymbol{R}_{\mathbf{1 r}}, \boldsymbol{R}_{\mathbf{2} \mathbf{r}}$ & Axial $\boldsymbol{R}_{\mathbf{1 a}}, \boldsymbol{R}_{\mathbf{2 a}}$ \\
\hline$R_{1 r}=R_{2 r}=\frac{\left(r_{1}-r_{2}\right)}{4 \lambda_{r} \pi r_{m} l}$ & $R_{1 a}=R_{2 a}=\frac{l}{2 \lambda_{a}\left(r_{1}^{2}-r_{2}^{2}\right)}$ \\
\hline
\end{tabular}

\subsection{Thermal Network Unit of "I" Type}

The thermal network unit definition of " $\mathrm{I}$ " type only includes radial thermal resistance, which are $R_{1 \mathrm{r}}$ and $R_{2 \mathrm{r}}$, as given in Figure $2 \mathrm{c}$ and Table 3. 
Table 3. Thermal resistance definition of "I" type [6].

\begin{tabular}{cc}
\hline Radial $\boldsymbol{R}_{\mathbf{1 r}}$ & Radial $\boldsymbol{R}_{\mathbf{2 r}}$ \\
\hline$R_{1 r}=\frac{1}{2 \pi \lambda_{r} l} \ln \left(\frac{r_{m}}{r_{2}}\right)$ & $R_{2 r}=\frac{1}{2 \pi \lambda_{r} l} \ln \left(\frac{r_{1}}{r_{m}}\right)$ \\
\hline
\end{tabular}

Take stator yoke iron core as example; its dimensions are $\Phi_{\text {yo_o }} \times \Phi_{\text {yo_i }} \times L_{\text {ef }}: 208 \times 178$ $\times 120(\mathrm{~mm})$. According to theoretical equations of thermal resistance unit in Tables 1-3, the calculation results of three kinds of thermal network unit are given in Table 4 .

Table 4. Thermal resistance results with three methods.

\begin{tabular}{ccccc}
\hline $\begin{array}{c}\text { Thermal } \\
\text { Resistance }\end{array}$ & \multicolumn{2}{c}{ Radial $\boldsymbol{R}_{\mathbf{r}}(\mathbf{K} / \mathbf{W})$} & \multicolumn{2}{c}{ Axial $\boldsymbol{R}_{\mathbf{a}}(\mathbf{K} / \mathbf{W})$} \\
\hline & $R_{1 \mathrm{r}}$ & 0.0023 & $R_{1 \mathrm{a}}$ & 1.466 \\
"H" type & $R_{2 \mathrm{r}}$ & 0.0022 & $R_{2 \mathrm{a}}$ & 1.466 \\
& $R_{3 \mathrm{r}}$ & $-7.63 \times 10^{-4}$, & $R_{3 \mathrm{a}}$ & -0.489 \\
& $R_{1 \mathrm{r}}$ & 0.0023 & $R_{1 \mathrm{a}}$ & 1.466 \\
& $R_{2 \mathrm{r}}$ & 0.0023 & $R_{2 \mathrm{a}}$ & 1.466 \\
& $R_{1 \mathrm{r}}$ & 0.0024 & - & - \\
& $R_{2 \mathrm{r}}$ & 0.0022 & - & - \\
\hline
\end{tabular}

Due to radial thermal conductivity $\lambda_{\mathrm{r}}=45 \mathrm{~W} /(\mathrm{m} \cdot \mathrm{K})$ being much larger than axial thermal conductivity $\lambda_{\mathrm{a}}=4.5 \mathrm{~W} /(\mathrm{m} \cdot \mathrm{K})$, radial resistance $R_{\mathrm{r}}$ is much less than axial resistance $R_{a}$. For the thermal network unit of the stator iron core and rotor iron core, heat transfer in the axial direction may be negligible. Therefore, we can approximately substitute "I" type for "H" type and "+" type, which can obviously reduce matrix size and computational burden.

\section{Transient Thermal Network Method of First Order}

In this section, a multi-node LPTN model of IPMSM is established based on the "+" type of thermal network unit. A heat capacity matrix, thermal conductivity matrix and node loss matrix of LPTN are established. A first-order, non-homogeneous linear differential equation is solved through discretization, and the temperature rise curves of each node changing with time step iteration are obtained. Operating conditions considering copper resistivity variation are analyzed based on the LPTN.

\subsection{First-Order Transient LPTN Theory}

Thermal flux $q_{s e c}$ (heat flow intensity) through the unit section area $\left(\mathrm{W} / \mathrm{m}^{2}\right)$ is given as

$$
q_{s e c}=\lambda \frac{\partial T}{\partial d}=h\left(T_{a c t}-T_{0}\right)
$$

where $h$ is the convection heat transfer coefficient $\left(\mathrm{W} / \mathrm{m}^{2} \cdot{ }^{\circ} \mathrm{C}\right), T_{a c t}$ is the actual temperature of the steady state $\left({ }^{\circ} \mathrm{C}\right), T_{0}$ is ambient temperature $\left({ }^{\circ} \mathrm{C}\right)$ and $d$ is thickness in the direction of heat conduction $(\mathrm{m})$.

Thermal flux $q_{\text {sec }}$ through cross-sectional area $A_{\text {sec }}$ is a constant. It eventually reaches the steady-state temperature (generated heat equals dissipated heat) by convection, as shown in

$$
P_{\text {loss }}(t)=h\left(T_{a c t}(t)-T_{0}\right) A_{s e c}=q A_{s e c}
$$

where $A_{s e c}$ is the outer circumferential surface area of the stator yoke iron core $\left(\mathrm{m}^{2}\right)$.

The temperature rise $T(t)$ is described by an exponential decay function as below.

$$
T(t)=P_{l o s s}(t) R_{e q}\left(1-e^{-t /\left(R_{e q} C_{e q}\right)}\right)
$$




$$
T_{a c t}(t)=T(t)+T_{0}
$$

where $R_{e q}$ is equivalent thermal resistance $\left(R_{e q}=R_{c o n d}+R_{c o n v}\right)$ and $C_{e q}$ is equivalent thermal capacity $\left(C_{e q}=C\right)$.

It is assumed that the stator yoke core generates a continuous power loss of $P_{\text {sta_yo }}=410 \mathrm{~W}$ (heat source $P_{\text {sta_yo }}$ is constant) and is dissipated by a single end face. If the LPTN unit is composed of a single heat source, its thermal resistance and thermal capacity are as shown in Figure 3a. The heat is transferred in a single direction, and its corresponding first thermal network is defined in Figure $3 \mathrm{~b}$. The heat transfer process is defined from one end face to another, which leads to a temperature rise $\left(T_{\text {act }}-T_{0}\right)$ in the yoke iron core. Similarly, the first-order model and its thermal network with air clearance are given in Figure 4a,b.

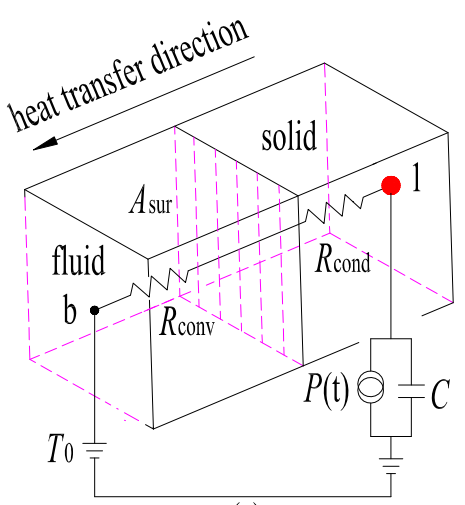

(a)

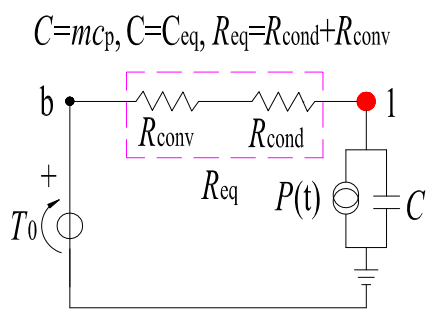

(b)

Figure 3. First-order model without air clearance and its thermal network. (a) First-order model, (b) first-order thermal network.

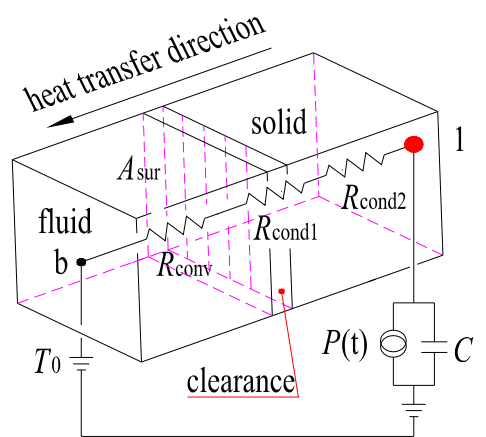

(a)

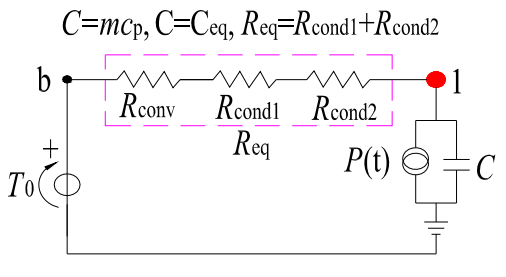

(b)

Figure 4. First-order model with air clearance and its thermal network. (a) First-order model, (b) first-order thermal network.

If an end face has convection with the ambient air, thermal-convection resistance $R_{\text {conv }}$ should be connected with thermal-conduction resistance $R_{\text {cond }}$ in series. The smaller the convective thermal resistance, the stronger the convective heat transfer ability; the range covers air cooling to water cooling. The more heat is dissipated to the ambient air, the lower the temperature rise of the cuboid itself. If there is no convective thermal resistance $R_{\text {conv }}$ to the ambient air, the boundary of the cuboid is an isothermal boundary, which reaches the limits of the thermal convection capacity.

When the convective heat transfer coefficient $\alpha$ takes different values with or without assembly clearance $\left(h_{\mathrm{ac}}=0.03 \mathrm{~mm}\right)$, the transient temperature curve with time is obtained, as shown in Figure 5 . For the given stator yoke loss $\left(P_{\text {sta_yo }}=410 \mathrm{~W}\right)$, the time of reaching the node steady temperature depends on the cooling ability of heat dissipation to the ambient air and thermal resistance along the heat transfer path. In other words, the increase in heat transfer convection coefficient $\alpha$ and the decrease in assembly clearance 
help to reduce the node temperature rise and shorten the time to reach the steady state (about 2500 s).
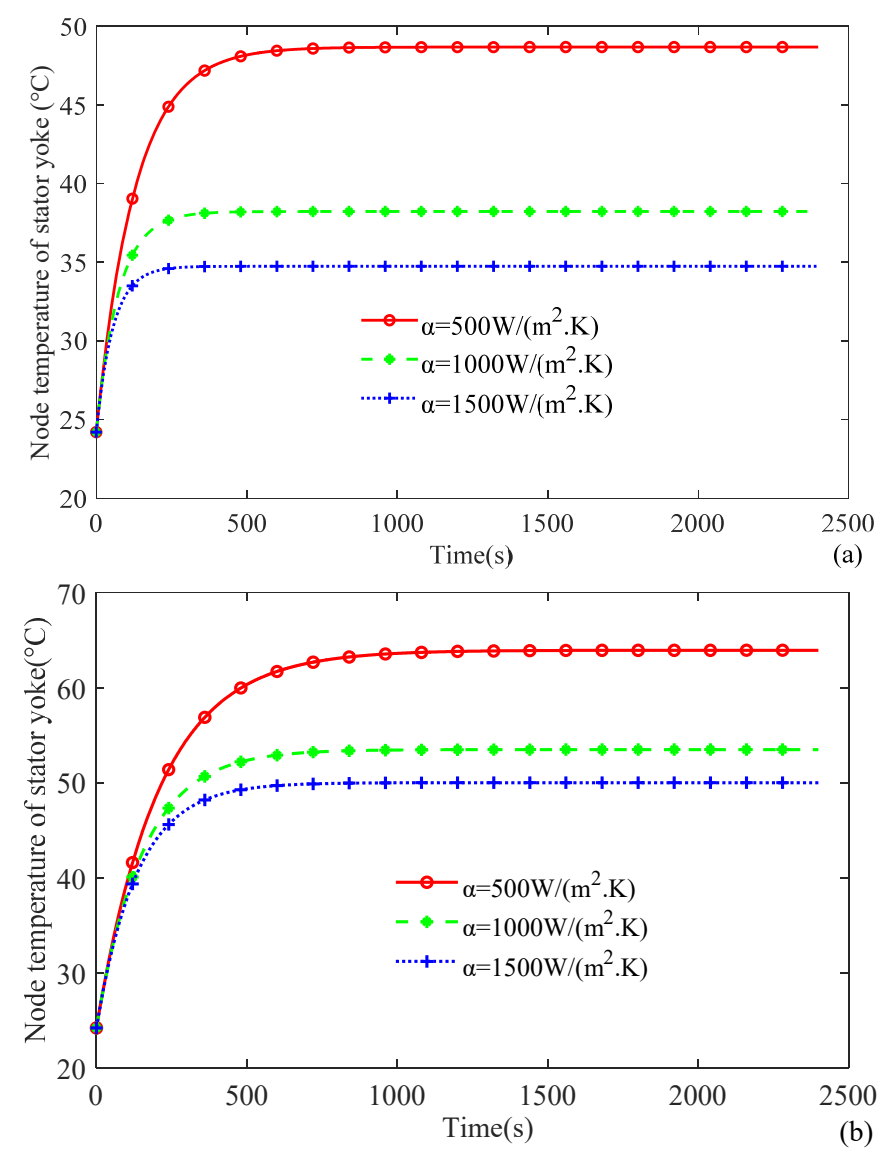

Figure 5. Transient temperature curve of stator yoke iron for different $\alpha$. (a) Direct cooling condition, (b) indirect cooling.

\subsection{Multi-Order LPTN Theory}

The transient temperature rise can be solved by the following differential equation.

$$
\begin{gathered}
Q(t)=\rho V c \Delta T=C \Delta T=[P(t)-G T(t)] \Delta t \\
\dot{T}(t)>>\frac{T(t+\Delta t)-T(t)}{\Delta t}=C^{-1}[P-G T(t)]
\end{gathered}
$$

where the part density $\rho$, part volume $V$, part mass $m$, specific heat capacity $c$ and thermal capacity $C$ are nxn diagonal matrixes, respectively. $\Delta T$ is the column vector of the temperature difference value. $Q(t)$ is the quantity of heat and $P(t)$ is the power loss of part node (W). $G$ is the nxn thermal conductivity symmetric matrix $\left(\mathrm{W} /{ }^{\circ} \mathrm{C}\right) . T$ is the column vector of temperature rise $\left({ }^{\circ} \mathrm{C}\right)$.

If the change in resistivity caused by temperature rise is considered, the loss matrix $P(t)$ should update in every time step. The change rate of the temperature rise matrix can be obtained by solving the first-order inhomogeneous differential equation $T(t)$.

$$
\dot{T}(t)=C^{-1} P(t)-C^{-1} G T(t)
$$

The general solution of the first-order inhomogeneous differential equation is the sum of the general solution of the corresponding homogeneous linear equation and a particular 
solution of the inhomogeneous linear equation, where the constant term of the general solution of the homogeneous linear equation is $C_{c o n}=T\left(t_{0}\right)$.

$$
T(t)=T\left(t_{0}\right) e^{-C^{-1} G\left(t-t_{0}\right)}+\int_{t_{0}}^{t} e^{-C^{-1} G(t-\tau)} d \tau C^{-1} P(t)
$$

The continuous equation in (10) is discretized with (11). At time $(n+1) \Delta t$ and $n \Delta t$, the temperature relation between $T[(n+1) \Delta t]$ and $T(n \Delta t)$ is given by

$$
T[(n+1) \Delta t]=e^{-C^{-1} G \Delta t} T(n \Delta t)-G^{-1} C\left(e^{-C^{-1} G \Delta t}-I\right) C^{-1} P(n \Delta t), n=0,1,2 \cdots
$$

The actual temperature $T_{\text {act }}(n \Delta t)$ of each node is the sum of the ambient temperature $T_{a m b}$ and the node temperature rise $T(n \Delta t)$.

$$
T_{a c t}(n \Delta t)=T_{a m b}+T(n \Delta t)
$$

When the convergence criterion $(T(n+1) \Delta t-T(n) \Delta t) / T(n+1) \Delta t<\varepsilon$ is satisfied, the iteration process is terminated. We assume $n_{\max } \Delta t-\tau$ is equal to $u$. The steady-state temperature rise calculation is simplified as

$$
T\left(n_{\max } \Delta t\right)=\int_{t_{0}}^{n_{\max } \Delta t} e^{-C^{-1} G\left(n_{\max } \Delta t-\tau\right)} d \tau C^{-1} P(t)=G^{-1} P(t)
$$

According to Equations (7)-(13), the flow chart of the transient temperature rise calculation of IPMSM is given in Figure 6. The flow chart also describes the change process from ambient temperature $T_{a m b}$ to steady-state temperature $T_{\max }$.

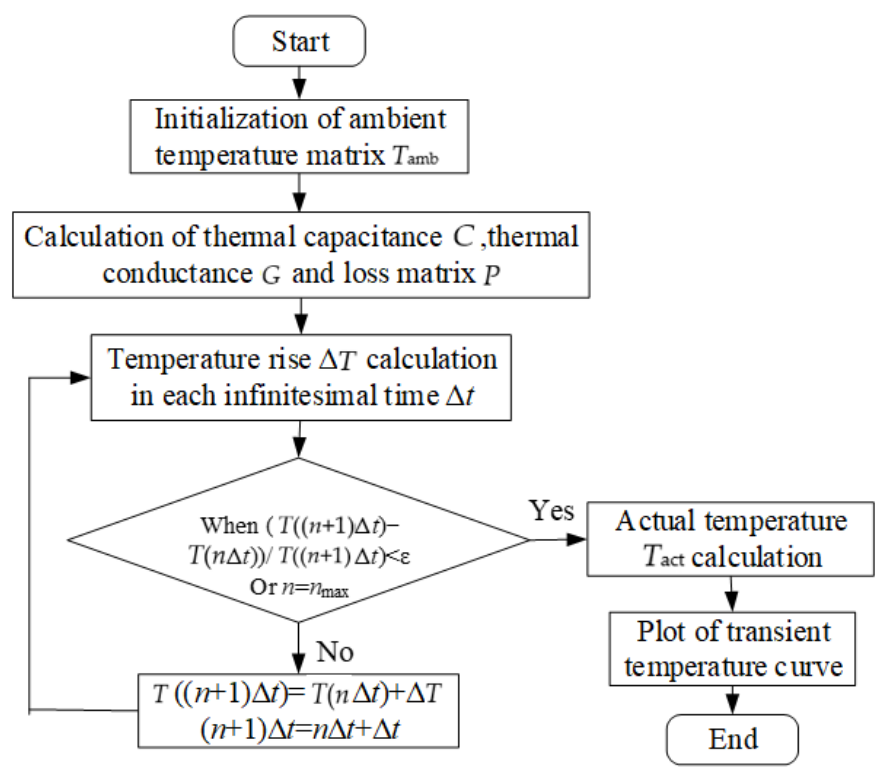

Figure 6. Flow chart of transient temperature calculation.

\section{Transient Thermal Network of IPMSM}

A half $40 \mathrm{~kW}$ IPMSM model and LPTN of temperature node distribution are built for its axial symmetry in Figure 7a,b in this paper. For the transient thermal network model, the IPMSM model is divided into the following 14 parts: (1) outer shell, (2) inner shell, (3) stator yoke, (4) stator tooth, (5) slotted winding, (6) end winding, (7) rotor shoe, (8) PM, (9) rotor yoke, (10) shaft, (11) end cap, (12) bearing, (13)-(14) inner air, (a), (c), (d) ambient air and (b) water. 


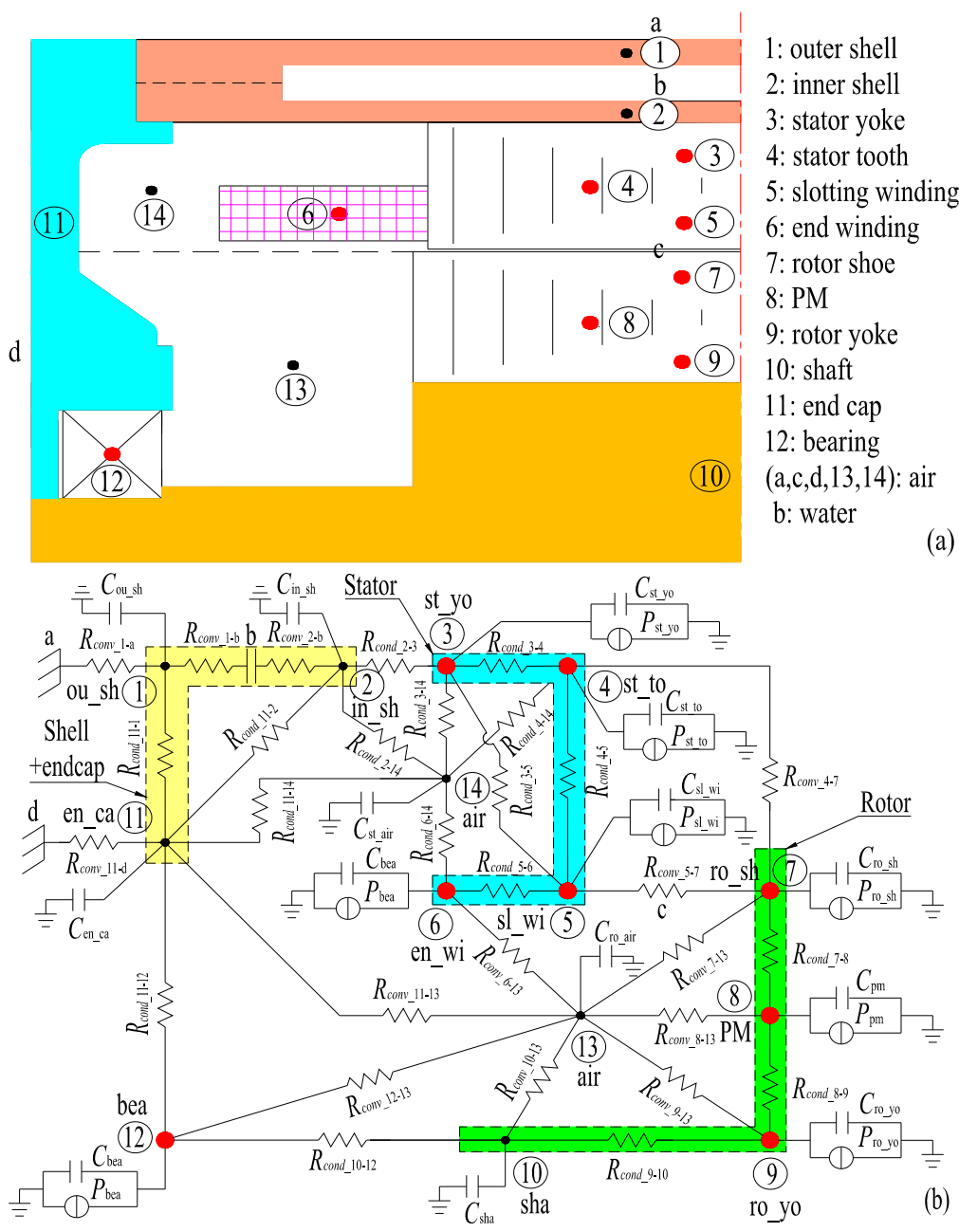

Figure 7. Node distribution and LPTN of IPMSM (a) node distribution, (b) LPTN.

Main heat generated by losses is taken away by circulating coolant in the shell. Therefore, the shell is divided into the outer shell (1\# node) and the inner shell (2\# node) considering heat convection. Due to the flux density difference between the stator tooth (3\# node) and the stator yoke (4\# node), losses of stator tooth and stator yoke are considered separately. Similarly, rotor iron loss falls into the rotor shoe (7\# node) loss and the rotor yoke (9\# node) loss. The winding is divided into slotting winding (5\# node) and end windings (6\# node). The end cap (11\# node) and the shaft (10\# node) are regarded as single non-heat source nodes. The wind friction loss is exerted on the rotor shoe (7\# node). Loss values for the heat generation are applied to heat source nodes of the IPMSM.

For the non-heat source nodes, thermal capacity and thermal resistance connected with adjacent nodes are considered. For the heat source nodes, thermal capacity, power loss and thermal resistance are considered. The transient thermal network model is given in detail in Figure $7 \mathrm{~b}$.

The main parameters of IPMSM are given in Table 5. Loss values for the heat generation are applied to the IPMSM parts. Loss values at rated load and node number are also given in Table 6 for the volume heat generation of IPMSM parts. 
Table 5. IPMSM Dimensions and Parameters.

\begin{tabular}{llll}
\hline Parameter & Value & & \\
\hline Bus voltage $U_{\mathrm{dc}}[\mathrm{V}]$ & 360 & Number of turns per coil $N_{\mathrm{s}}$ & 10 \\
Rated power $P_{\mathrm{n}}[\mathrm{kW}]$ & 40 & Length of air gap $\delta[\mathrm{mm}]$ & 1.5 \\
Rated speed $n[\mathrm{rpm}]$ & 4000 & PM thickness $h_{\mathrm{pm}}[\mathrm{mm}]$ & 6 \\
Inner diameter of stator iron $D_{\mathrm{si}}[\mathrm{mm}]$ & 150 & Number of stator slots $Q$ & 48 \\
Outer diameter of stator iron $D_{\mathrm{so}}[\mathrm{mm}]$ & 208 & Number of pole pairs $p$ & 4 \\
Length of stator iron $L_{\mathrm{ef}}[\mathrm{mm}]$ & 160 & Winding connection & $\mathrm{Y}$ \\
Number of parallel branches a & 2 & Coolant flow speed $V[\mathrm{~L} / \mathrm{min}]$ & 8 \\
\hline
\end{tabular}

Table 6. Loss value of IPMSM parts.

\begin{tabular}{lccc}
\hline Parameter & Symbol & Value & No. \\
\hline Stator yoke loss [W] & $P_{\text {Fej }}$ & 410 & 3 \\
Stator tooth loss [W] & $P_{\text {Fet }}$ & 282 & 4 \\
Slot winding loss [W] & $P_{\text {Cu1 }}$ & 810 & 5 \\
End winding loss [W] & $P_{\text {Cu2 }}$ & 651 & 6 \\
Rotor pole shoe loss [W] & $P_{\text {ros }}$ & 20 & 7 \\
PM eddy loss [W] & $P_{\text {pm }}$ & 38 & 8 \\
Rotor yoke iron loss [W] & $P_{\text {roy }}$ & 45 & 9 \\
Bearing loss [W] & $P_{\text {be }}$ & 0.11 & 12 \\
Air friction loss [W] & $P_{\text {air }}$ & 20 & 13 \\
\hline
\end{tabular}

Loss values at $40 \mathrm{~kW}$ power and speed of $4000 \mathrm{rpm}$.

\section{Load Case Analysis and Experiment}

Transient temperature rise considering actual copper resistivity and intermittent condition is analyzed in this section.

\subsection{Consant Load Considering Copper Resistivity}

Winding copper loss $P_{C u}$ of two groups of phases, phase resistance $R$ and copper resistivity $\rho$ considering electrical resistivity variation with temperature are defined as:

$$
\left\{\begin{array}{l}
P_{C u}=m I^{2} R_{0}(1+\alpha T)=m I^{2} R_{20}(1+\alpha(T-20)) \\
R=\rho_{0}(1+\alpha T) \frac{L}{S}=\rho_{20}(1+\alpha(T-20)) \frac{L}{S} \\
\rho=\rho_{0}(1+\alpha T)=\rho_{20}(1+\alpha(T-20))
\end{array}\right.
$$

where $T_{0}$ is ambient temperature $\left({ }^{\circ} \mathrm{C}\right), \rho_{0}$ is the electrical resistivity of copper at $0{ }^{\circ} \mathrm{C}$ $\left(\rho_{0}=0.0165 \Omega \mathrm{mm}^{2} / \mathrm{m}\right), \quad \rho_{20}$ is the electrical resistivity of copper at $20{ }^{\circ} \mathrm{C}$ $\left(\rho_{20}=0.0176 \Omega \mathrm{mm}^{2} / \mathrm{m}\right)$, and $\alpha$ is the temperature coefficient of copper $\left(\alpha=0.0039 /{ }^{\circ} \mathrm{C}\right)$. The winding copper resistivity $\rho$ increases slightly with the increase in temperature $\mathrm{T}$ as shown in Figure 8. 


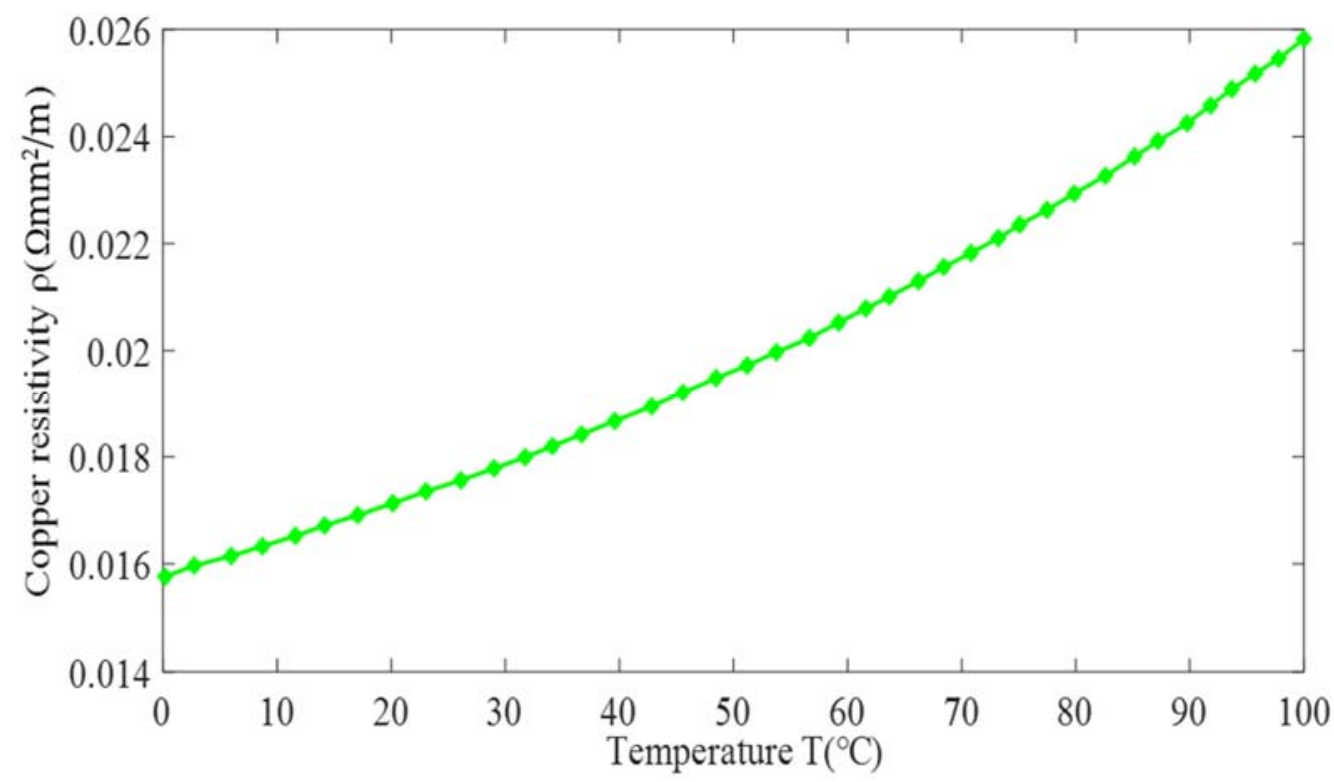

Figure 8. Copper resistivity variation with temperature.

Based on the LPTN of IPMSM in Figure 7b and Equations (7)-(13), transient node temperature curves of the main heat sources are given in Figure 9.

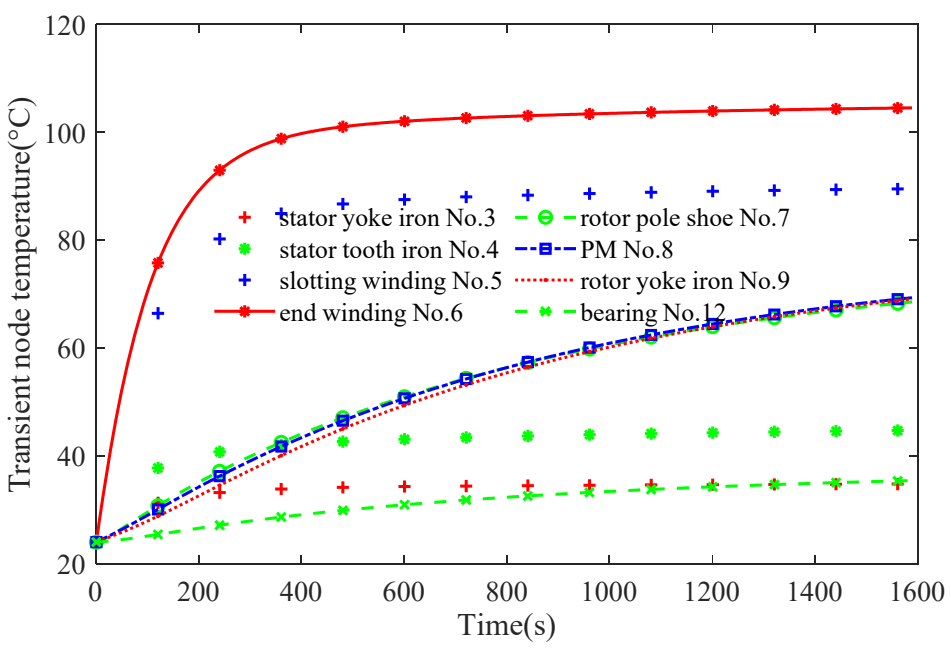

Figure 9. Transient temperature curve of different parts considering constant load.

First-order, second-order, and third-order exponential decay functions are used to predict the transient winding temperature for two operating points, which are given as

$$
\left\{\begin{array}{l}
y_{1 \mathrm{th}}(x)=A_{1} e^{-x / t_{1}}+y_{0} \\
y_{2 \operatorname{th}}(x)=A_{1} e^{-x / t_{1}}+A_{2} e^{-x / t_{2}}+y_{0} \\
y_{3 \operatorname{th}}(x)=A_{1} e^{-x / t_{1}}+A_{2} e^{-x / t_{2}}+A_{3} e^{-x / t_{3}}+y_{0}
\end{array}\right.
$$

where $y_{0}$ is the offset distance; $A_{1} \sim A_{3}$ are amplitude; $t_{1} \sim t_{3}$ are the decay constant.

The parameters of three kinds of exponential decay functions are calculated by origin as shown in Table 7. 
Table 7. Loss value of IPMSM parts.

\begin{tabular}{ccccc}
\hline \multirow{2}{*}{ Order } & \multicolumn{2}{c}{ Sym } & Value & \multicolumn{2}{c}{ Sym } & Value \\
\cline { 2 - 5 } & \multicolumn{2}{c}{$\mathbf{3 0 0 0} \mathbf{~ r p m - 4 0 ~} \mathbf{~ W}$} & \multicolumn{2}{c}{$\mathbf{6 0 0 0} \mathbf{~ p m - 4 0 ~} \mathbf{~ W}$} \\
\hline \multirow{3}{*}{1 st } & $y_{0}$ & 106.69 & $y_{0}$ & $\mathbf{8 0 . 1 8}$ \\
& $A_{1}$ & -78.64 & $A_{1}$ & -49.16 \\
& $t_{1}$ & 190.44 & $t_{1}$ & 300.55 \\
\hline \multirow{3}{*}{ 2nd } & $y_{0}$ & 109 & $y_{0}$ & 81.3 \\
& $A_{1}$ & -38.21 & $A_{1}$ & -12.23 \\
& $t_{1}$ & 372.11 & $t_{1}$ & 29.82 \\
$A_{2}$ & -46.26 & $A_{2}$ & -44.03 \\
& $t_{2}$ & 100.99 & $t_{2}$ & 371.06 \\
\hline \multirow{3}{*}{ 3rd } & $y_{0}$ & 109 & $y_{0}$ & 81.3 \\
& $A_{1}$ & -23.13 & $A_{1}$ & -12.23 \\
& $t_{1}$ & 101.01 & $t_{1}$ & 29.82 \\
& $A_{2}$ & -23.13 & $A_{2}$ & -21.95 \\
& $t_{2}$ & 100.97 & $t_{2}$ & 371.08 \\
& $A_{3}$ & -38.21 & $A_{3}$ & -22.08 \\
& $t_{3}$ & 372.11 & $t_{3}$ & 371.05 \\
\hline
\end{tabular}

Comparison between the measured transient winding temperature and nonlinear exponential fit curves are given for two operating points. The first operating case in Figure 10a is line voltage $U_{\mathrm{ab}}=196.6 \mathrm{~V}$, phase current $I_{\mathrm{a}}=203.1 \mathrm{~A}$, speed $n=3000 \mathrm{rpm}$ and $P_{\mathrm{n}}=40 \mathrm{~kW}$. The second operating case in Figure $10 \mathrm{~b}$ is line voltage $U_{\mathrm{ab}}=245.6 \mathrm{~V}$, phase current $I_{\mathrm{a}}=119.2 \mathrm{~A}$, speed $n=6000 \mathrm{rpm}$ and $P_{\mathrm{n}}=40 \mathrm{~kW}$. Winding temperature reaches the steady state after $1600 \mathrm{~s}$, which benefits from the excellent heat dissipation of the water cooling. We can see from Figure 10 that the exponential decay fit function of the second order and the third order has higher accuracy than that of the first order.
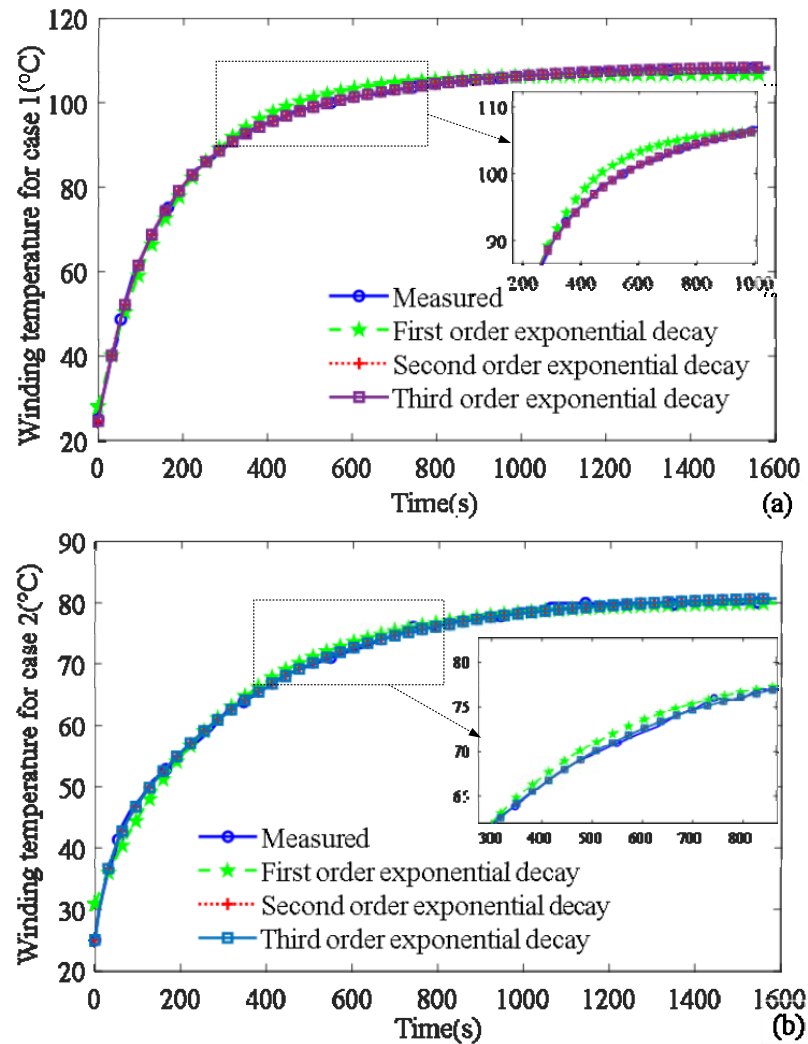

Figure 10. Measured winding temperature. (a) $3000 \mathrm{rpm}-40 \mathrm{~kW}$, (b) $6000 \mathrm{rpm}-40 \mathrm{~kW}$. 


\subsection{Rectangular Wave Load}

The copper loss curve of the rectangular periodic wave is discontinuous at the orthogonal turning point. Therefore, copper loss curve data expressed by Fourier series are loaded discretely. Slotting winding loss and end winding loss are applied to corresponding objects in the form of Fourier series. We set a period of $120 \mathrm{~s}$ and run 15 cycles. Winding loss is given as

$$
\left\{\begin{aligned}
P_{\text {slo_win }}(t) & =\alpha_{\mathrm{dt}}\left(A_{\text {slo_win1 }}-A_{\text {slo_win2 }}\right)+A_{\text {slo_win } 2} \\
& -\sum_{n=1}^{\infty} \frac{1}{n \pi}\left(\begin{array}{c}
2\left(A_{\text {slo_win } 1}-A_{\text {slo_win } 2}\right) \\
\sin \left(\alpha_{\mathrm{dt}} n \pi\right) \cos \left(n \omega t-\alpha_{\mathrm{dt}} n \pi\right)
\end{array}\right) \\
P_{\text {end_win }}(t) & =\alpha_{\mathrm{dt}}\left(A_{\text {end_win1 }}-A_{\text {end_win2 } 2}\right)+A_{\text {end_win2 }} \\
& -\sum_{n=1}^{\infty} \frac{1}{n \pi}\left(\begin{array}{c}
2\left(A_{\text {end_win1 } 1}-A_{\text {end_win2 }}\right) \cdot \\
\sin \left(\alpha_{\mathrm{dt}} n \pi\right) \cos \left(n \omega t-\alpha_{\mathrm{dt}} n \pi\right)
\end{array}\right)
\end{aligned}\right.
$$

where $\alpha_{\mathrm{dt}}$ is the duty cycle (here $\left.\alpha_{\mathrm{dt}}=0.5\right), A_{\text {slo_win1 }}$ and $A_{\text {slo_win2 }}$ are the upper and lower values of slotting winding loss (W), $A_{\text {end_win1 }}, A_{\text {end_win2 }}$ are the upper and lower values of end winding loss $(\mathrm{W})$, respectively, and $\omega$ is the angular frequency (rad/s).

Rectangular wave loss of slotting winding and end winding is given in Figure 11. A rectangular periodic step torque from light load to heavy load is simulated, which leads to the change of winding loss $\left(A_{\text {slo_win } 1}=810 \mathrm{~W}, A_{\text {slo_win2 }}=203 \mathrm{~W}, A_{\text {end_win1 }}=651 \mathrm{~W}\right.$, $A_{\text {end_win2 }}=155 \mathrm{~W}$ ). The thermal source matrix is updated at every time step and transient temperature curves of slotting winding and end winding are given in Figure 12. We can find that the calculation result of LPTN agrees well with the outcome of the experiment. For the slotting winding at the steady state, there is about an $8{ }^{\circ} \mathrm{C}$ error between the measurement value and the LPTN value. The reason for the higher value is that the value of thermal resistance or winding loss may be high for single node modeling.
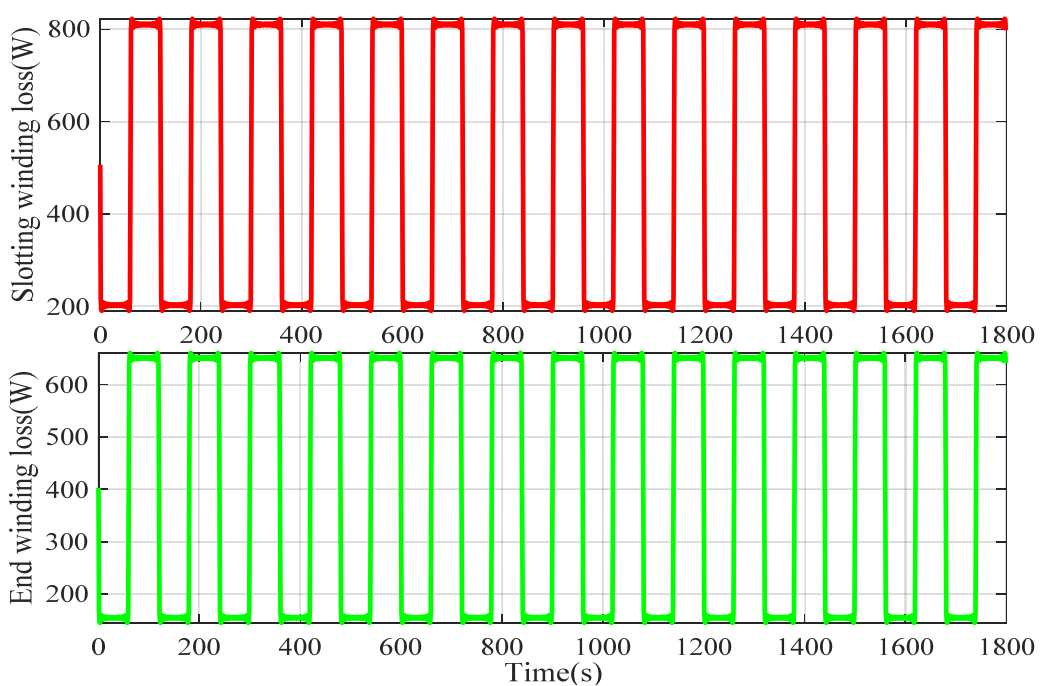

Figure 11. Slotting and end winding losses in the form of rectangular wave load. 


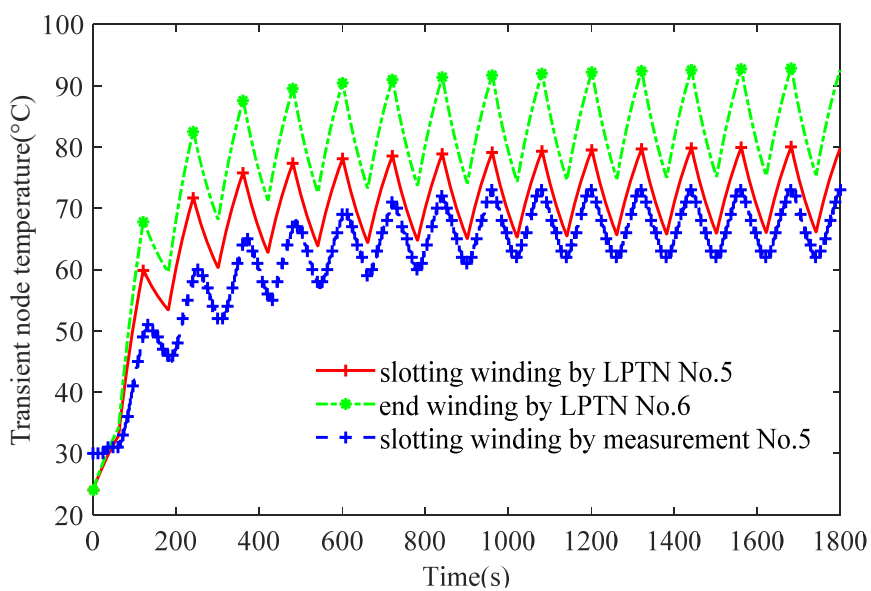

Figure 12. Transient temperature curve of end and slotting winding considering rectangular wave load.

In order to verify the LPTN model, the prototype of 48-slot/8-pole IPMSM with "V" type rotor and ISDW stator is designed and manufactured. The stator and rotor are shown in Figure 13. A load test platform is established to validate its temperature rise and output characteristics, as shown in Figure 14.

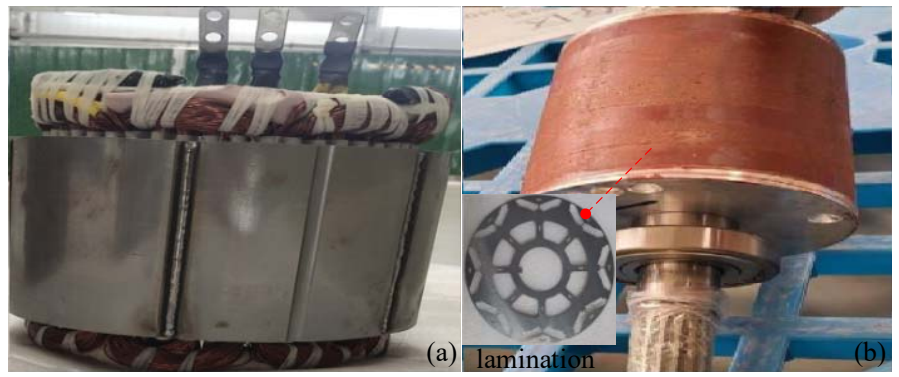

Figure 13. IPMSM component. (a) Stator, (b) rotor.
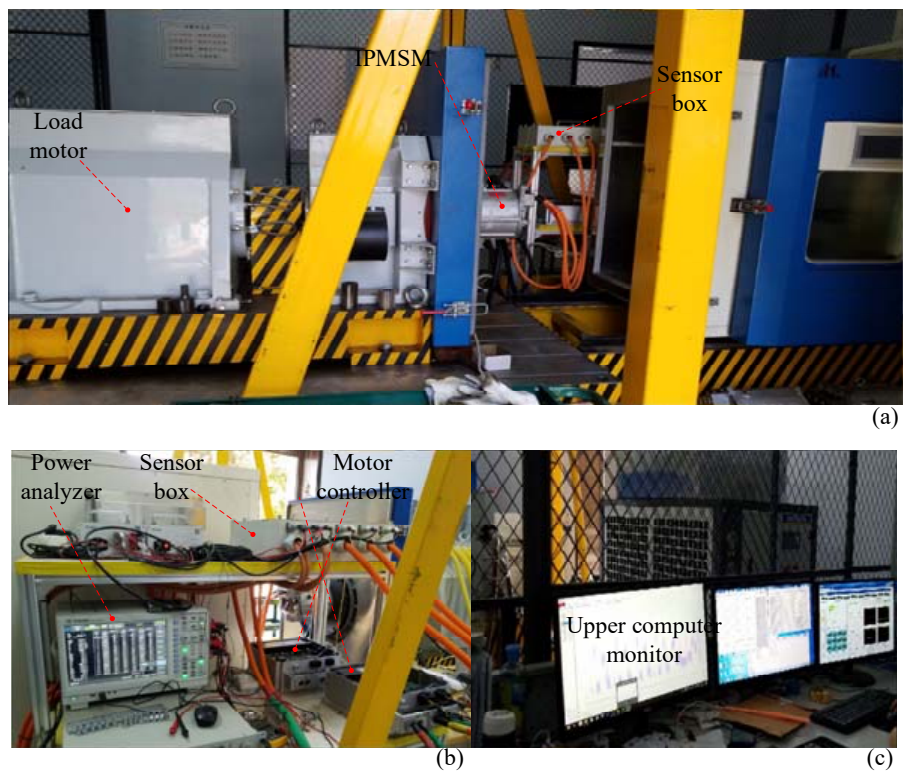

Figure 14. Dynamometer platform. (a) Dynamometer, (b) data acquisition system, (c) upper computer monitor. 
The measured phase current wave using three AC current clamps under rated load conditions is shown in Figure 15A, whose peak value reaches $232 \mathrm{~A}$. The phase current under overload conditions is obtained in Figure 15B, whose peak value reaches $382 \mathrm{~A}$.
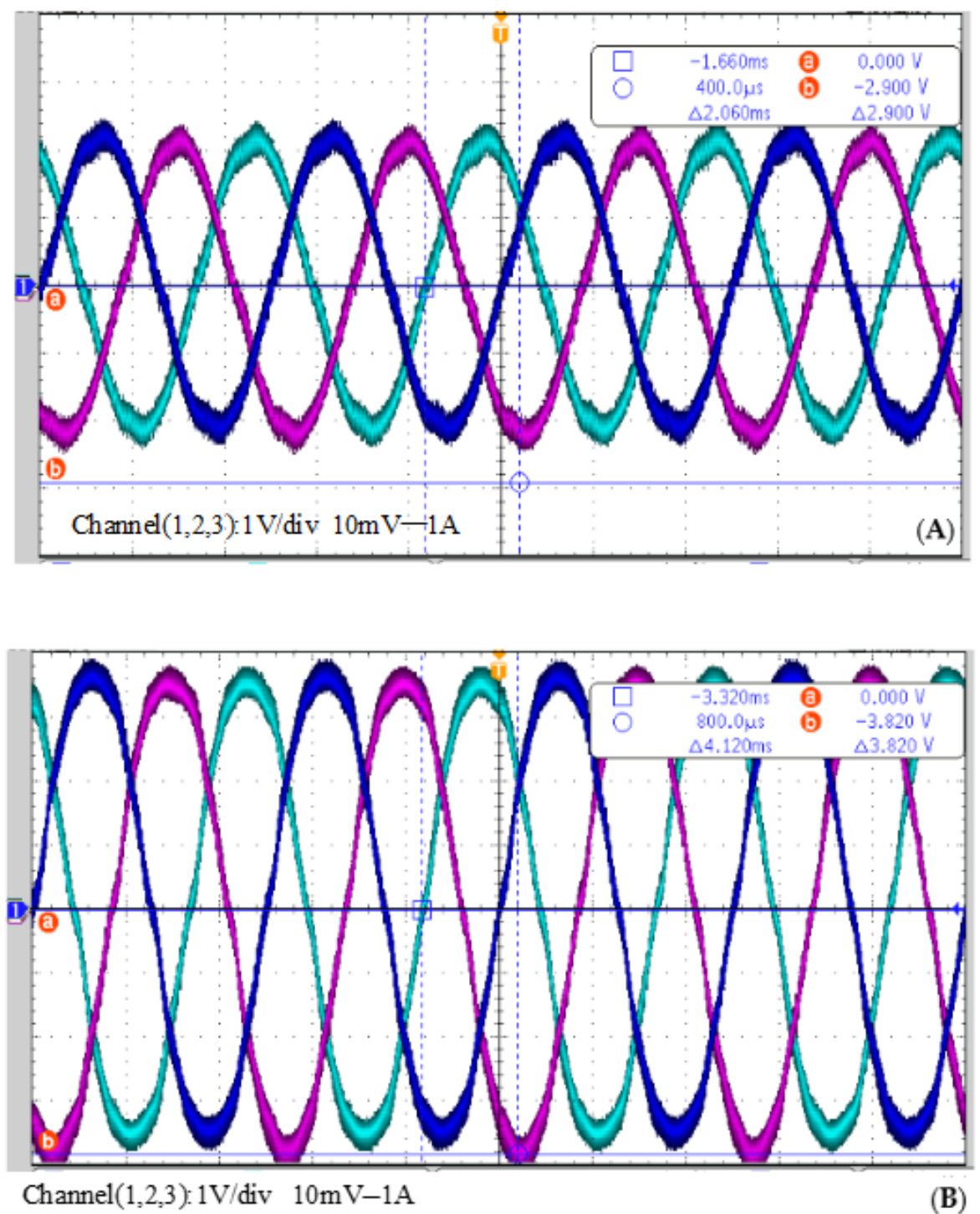

Figure 15. Phase current wave. (A) rated load, (B) overload.

The temperature of the IPMSM parts is measured by thermocouple PTC100 and a FLUKE infrared imaging device. Thermocouple temperature sensors PTC100 are inserted into slotted windings for measuring the temperature of the slotted winding. The outer surface temperature of the IPMSM is measured by using a FLUKE infrared imaging device in Figure 16. 


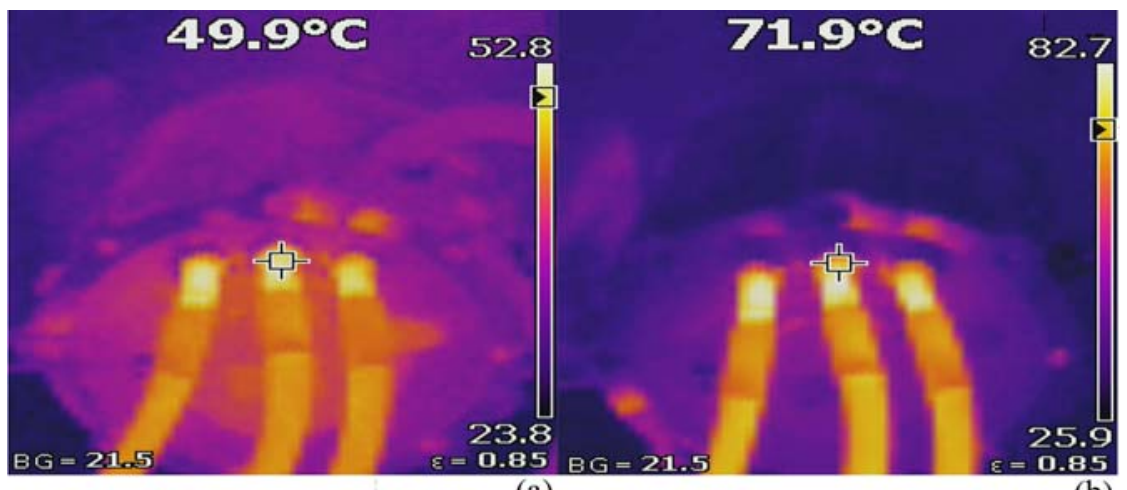

(a)

(b)

Figure 16. Infrared thermal image. (a) $T=119 \mathrm{~N} \cdot \mathrm{m}, n=4000 \mathrm{rpm}, I_{\mathrm{a}}=151 \mathrm{~A}$, (b) $T=295 \mathrm{~N} \cdot \mathrm{m}$, $n=2000 \mathrm{rpm}, I_{\mathrm{a}}=351 \mathrm{~A}$.

The measured IPMSM efficiency versus different load torques at $3000 \mathrm{rpm}$ and $6000 \mathrm{rpm}$ are given in Figure 17. We found that efficiency is higher at a rated speed of $3000 \mathrm{rpm}$. Due to a large copper loss and iron loss in the field-weakening region, efficiency is relatively low. A measured IPMSM efficiency map including constant torque and constant power operating regions is given in Figure 18. The operating point of the NEDC duty cycle is also obtained by the test platform as shown in Figure 18. We found that the maximum efficiency of IPMSM reaches about 97\%; however, the relatively low efficiency in the constant power operation region ranges from $80 \%$ to $87 \%$ for the NEDC duty cycle.

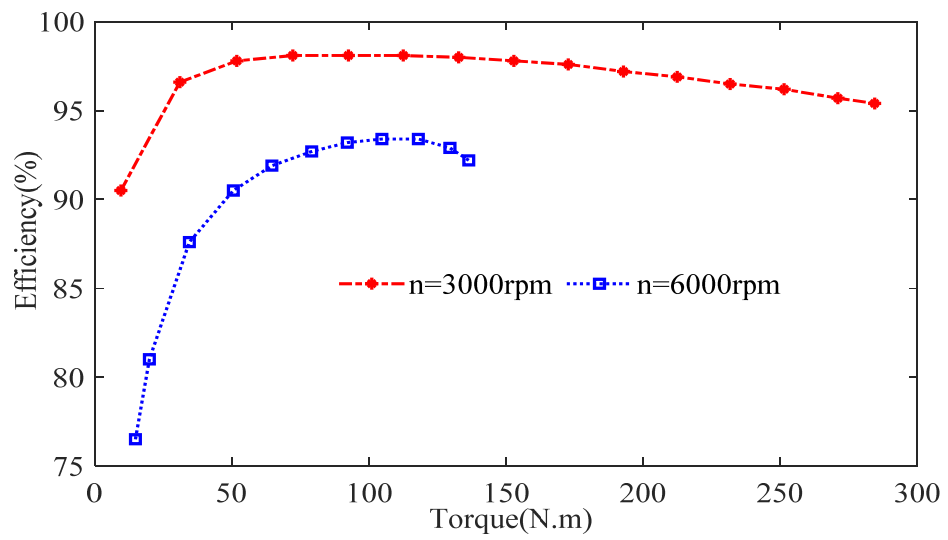

Figure 17. Measured efficiency versus torque at speed $n=3000 \mathrm{rpm}$ and $n=6000 \mathrm{rpm}$.

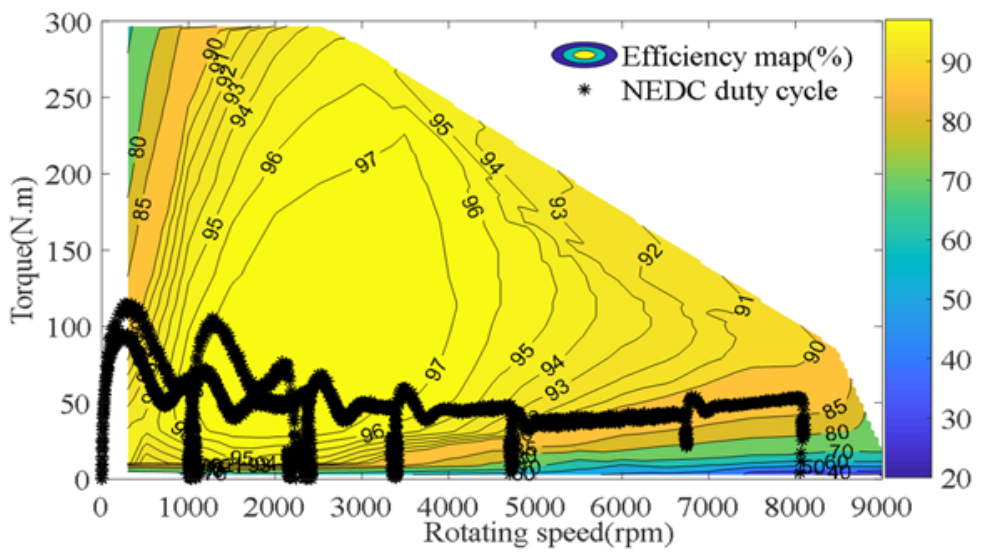

Figure 18. Measured efficiency and operating point of NEDC duty cycle. 


\section{Conclusions}

The method of the first-order LPTN is deduced by solving the non-homogeneous linear differential equation. The results show that the heat transfer coefficient of fluid and thickness of air gap layer are the main influencing factors for reaching a steady temperature. The larger the heat transfer coefficient of fluid is, the lower the steady node temperature is. The smaller the air layer thickness is, the lower the steady node temperature is.

Furthermore, the multi-order LPTN theory is deduced based on the extension of firstorder transient LPTN. For the constant load and rectangular periodic load, the transient node temperatures of IPMSM are obtained by modeling transient LPTN and solving the non-homogeneous linear differential equation. Compared with the experimental data, exponential decay fit function of the second order and the third order has higher accuracy than that of the first order, which can serve as an alternative to full-order thermal networks.

The temperature rise experiment platform including IPMSM manufacture is established to validate the above-mentioned method using a FLUKE infrared thermal imager and thermocouple PTC100. Load current and efficiency maps are obtained using the dynamometer platform. The load experiment shows that the transient LPTN of the IPMSM can accurately predict node temperature variation.

Author Contributions: Methodology and formula derivation, Q.C.; writing and original draft preparation, Q.C. and D.W.; review and editing, W.C. and Z.Q.; supervision, G.L.; project administration, Q.W. All authors have read and agreed to the published version of the manuscript.

Funding: This research was funded by Key Project of the China National Natural Science Foundation (Project number: 51637001); Open Fund for National Engineering Laboratory of Energy-Saving Motor \& Control Technology, Anhui University (KFKT202101).

Institutional Review Board Statement: Not applicable.

Informed Consent Statement: Not applicable.

Data Availability Statement: Not applicable.

Conflicts of Interest: The authors declare no conflict of interest.

\section{References}

1. Zhang, B.; Qu, R.H.; Wang, J.; Xu, W.; Fan, X.G.; Chen, Y. Thermal model of totally enclosed water-cooled permanent-magnet synchronous machines for electric vehicle application. IEEE Trans. Ind. Appl. 2015, 51, 3020-3029. [CrossRef]

2. Okoro, O.I. Steady and transient states thermal analysis of a 7.5-kW squirrel-cage induction machine at rated-load operation. IEEE Trans. Energy Convers. 2005, 20, 730-736. [CrossRef]

3. Boglietti, A.; Cossale, M.; Popescu, M.; Staton, D.A. Electrical machines thermal model: Advanced calibration techniques. IEEE Trans. Ind. Appl. 2019, 55, 2620-2628. [CrossRef]

4. Boglietti, A.; Cossale, M.; Vaschetto, S.; Dutra, T. Thermal conductivity evaluation of fractional-slot concentrated-winding machines. IEEE Trans. Ind. Appl. 2017, 53, 2059-2065. [CrossRef]

5. Sciascera, C.; Giangrande, P.; Papini, L.; Gerada, C.; Galea, M. Analytical thermal model for fast stator winding temperature prediction. IEEE Trans. Ind. Electron. 2017, 64, 6116-6126. [CrossRef]

6. Boglietti, A.; Carpaneto, E.; Cossale, M.; Vaschetto, S. Stator-winding thermal models for short-time thermal transients: Definition and validation. IEEE Trans. Ind. Electron. 2016, 63, 2713-2721. [CrossRef]

7. Vansompel, H.; Yarantseva, A.; Sergeant, P.; Crevecoeur, G. An inverse thermal modeling approach for thermal parameter and loss identification in an axial flux permanent magnet machine. IEEE Trans. Ind. Electron. 2019, 63, 1727-1735. [CrossRef]

8. Chen, Q.; Li, G.; Cao, W.; Qian, Z.; Wang, Q. Winding MMF and PM MMF analysis of axial-flux machine with multi-phase and multi-layer winding. Energies 2021, 14, 5147. [CrossRef]

9. Chen, Q.; Liang, D.; Jia, S.; Ze, Q.; Liu, Y. Analysis of winding MMF and loss for axial flux PMSM with FSCW layout and YASA topology. IEEE Trans. Ind. Appl. 2020, 56, 2622-2635. [CrossRef]

10. Qi, J.; Hua, W.; Zhang, H.L. Thermal analysis of modular-spoke-type permanent-magnet machines based on thermal network and FEA method. IEEE Trans. Magn. 2019, 55, 8104105. [CrossRef]

11. Vansompel, H.; Rasekh, A.; Hemeida, A. Coupled electromagnetic and thermal analysis of an axial flux PM machine. IEEE Trans. Magn. 2015, 51, 8108104. [CrossRef]

12. Nasab, P.S.; Perini, R.; Gerlando, A.D. Analytical thermal model of natural-convection cooling in axial flux machines. IEEE Trans. Ind. Electron. 2020, 67, 2711-2721. [CrossRef] 
13. Chen, Q.X.; Zou, Z.Y.; Cao, B.G. Lumped-parameter thermal network model and experimental research of interior pmsm for electric vehicle. CES Trans. Electr. Mach. Syst. 2017, 1, 367-374. [CrossRef]

14. Chen, Q.; Liang, D.; Gao, L.; Wang, Q.; Liu, Y. Hierarchical thermal network analysis of axial flux permanent magnet synchronous machine for electric motorcycle. IET Electr. Power Appl. 2018, 12, 859-866. [CrossRef]

15. Fan, X.G.; Li, D.W.; Qu, R.H.; Wang, C. A dynamic multilayer winding thermal model for electrical machines with concentrated windings. IEEE Trans. Ind. Electron. 2019, 66, 6189-6199. [CrossRef]

16. Zhang, Y.; McLoone, S.; Cao, W.P. Power loss and thermal analysis of a MW high-speed permanent magnet synchronous machine. IEEE Trans. Energy Convers. 2017, 32, 1468-1478. [CrossRef]

17. Nerg, J.; Rilla, M.; Pyrhönen, J. Thermal analysis of radial-flux electrical machines with a high power density. IEEE Trans. Ind. Electron. 2008, 55, 3543-3554. [CrossRef]

18. Rostami, N.; Feyzi, M.R.; Pyrhonen, J.; Parviainen, A.; Niemela, M. Lumped-parameter thermal model for axial flux permanent magnet machines. IEEE Trans. Magn. 2013, 49, 1178-1184. [CrossRef]

19. Mellor, P.D.; Roberts, D.; Turner, D.R. Lumped parameter thermal model for electrical machines of TEFC design. Proc. Inst. Electr. Eng. B 1991, 138, 205-218. [CrossRef] 